\title{
Propiedades Psicométricas de una Escala de Estilos Parentales e Inconsistencia Parental Percibida (EPIPP).
}

\author{
Guadalupe de la Iglesia *1, Paula Ongarato* \& Mercedes Fernández Liporace ** \\ * Lic. en Psicología. Universidad de Buenos Aires. Argentina - CONICET. \\ ** Dra. en Psicología. Universidad de Buenos Aires. Argentina-CONICET.
}

\begin{abstract}
Resumen: Se presentan las propiedades psicométricas de la EPIPP, una escala diseñada para la medición de Estilos Parentales e Inconsistencia Parental Percibida en adultos jóvenes. Su validez de contenido fue abordada mediante la valoración de jueces expertos. El análisis de ítems incluyó el examen de frecuencias de respuesta, de índices de homogeneidad corregidos y estudios de asimetría y curtosis. Se buscaron evidencias de validez de constructo por medio de un estudio factorial exploratorio en el que se aislaron estructuras idénticas para las versiones PADRE y MADRE. Ambas estaban constituidas por seis subescalas: Afecto, Diálogo, Indiferencia, Coerción Verbal, Coerción Física y Prohibición. A su vez, estas se agruparon en asimismo, en dos escalas mayores (Respuesta y Demanda) resultantes de un estudio factorial de segundo orden. Finalmente, se evaluó la consistencia de las dimensiones a través del cálculo de Alfas de Cronbach y de Alfas ordinales y se verificó una adecuada estabilidad de las puntuaciones en un estudio test-retest.

Palabras clave: : Estilos Parentales; Inconsistencia Parental; Validez de Constructo.
\end{abstract}

Title: Psychometric Properties of a Perceived Parenting Styles And Inconsistency Scale (EPIPP)

Abstract: This paper presents psychometric properties of the EPIPP, a scale designed to measure Perceived Parenting Styles and Parental Inconsistency in young adults. Its content validity was analyzed by means of experts. Item analysis consisted in the examination of answering frequencies, corrected homogeneity indexes and skewness and kurtosis values. Evidences of construct validity were sought by an exploratory factor study, which resulted in identical solutions for FATHER and MOTHER versions. They were both comprised by six subscales: Affection, Dialogue, Indifference, Verbal Coercion, Physical Coercion and Prohibition. They grouped in two major scales (Reponsiveness and Demandingness) through a second-order factor analysis. Finally, consistency was analyzed by calculating Cronbach's Alphas and ordinal Alphas coefficients. Temporal stability of scores was evaluated by a test-retest procedure.

Key Words: Parenting Styles; Parenting Inconsistency; Construct Validity.

\section{Introducción}

El estudio de la influencia de los estilos parentales sobre el desarrollo psicológico de los hijos se ha focalizado principalmente en población infantil y adolescente. Los adultos jóvenes no han sido especial objeto de análisis a pesar de que se ha puesto de relieve que el modo en que se ejerce la crianza redunda en efectos a lo largo de todo el ciclo vital (Anisman, Zaharia, Meaney \& Merali, 1998; Maccoby, 1994; Rohner \& Veneziano, 2001; Rothrauff, Cooney \& An, 2009). Estos abordajes han indicado la importancia de considerar la percepción que los individuos tienen de las conductas de los padres antes que el

\footnotetext{
${ }^{1}$ Por favor dirigir la correspondencia relacionada con este artículo a: Guadalupe de la Iglesia, E-mail: gdelaiglesia@psi.uba.ar.

Dirección postal: Instituto de Investigaciones en Psicología, Av. Independencia 3065, 3er. Piso, CP: C1225AAM, Ciudad Autónoma de Buenos Aires, Argentina. Tel: 5411- 4957-5886/5887.

Este trabajo se realizó con subsidio UBACyT y con el aval de la Universidad de Buenos Aires y el CONICET.
} 
comportamiento real de estos últimos (Acock \& Bengtson, 1980; Ausubel, Baltasar, Rosenthal, Blackman, Schpoont \& Welkowitz, 1954; Schaefer, 1965; Serot \& Teevan, 1961).

La medición de los estilos parentales ha sido encarada de dos modos distintos: dimensionalmente y en forma categorial. Por una parte, se postularon dimensiones globales componentes del fenómeno, usualmente identificadas como respuesta y demanda (muchas veces también nominadas como afectividad y control). La primera, comprende manifestaciones de cariño, diálogo, implicación, contención, apoyo, calidez; la segunda, incluye exigencias, límites, prohibiciones, castigos, reglas o normas, disciplina. Varios autores se han dedicado durante décadas al estudio de alguno de estos aspectos del concepto, buscando vincularlos con resultados diversos en la salud psicofísica (e.g. Baumrind, 1966, 1971, 1978, 1980, 1991a, 1991b, 1994, 1996a, 1996b; Dwairy, 2007; Dwairy \& Dor, 2009; Rohner, 2004, 2008; Rohner \& Britner, 2002).

Por otra parte, en un enfoque diferente y de acuerdo con criterios teóricos o estadísticos, se construyeron distintas categorizaciones de los estilos de parentalidad. La más utilizada es aquella propuesta por Maccoby y Martin (1983), que postula cuatro estilos constituidos mediante la combinación de las dos dimensiones antes nombradas: el autoritario (alta demanda y baja respuesta), el permisivo (baja demanda y alta respuesta), el negligente (baja demanda y baja respuesta) y el autoritativo (alta demanda y alta respuesta). Este último fue acuñado teóricamente en primera instancia por Baumrind (1966) y está relacionado con consecuencias salugénicas.

A pesar de su extendido uso, esta tipología resulta limitada puesto que no contempla la posibilidad del estilo sobreprotector, que se caracteriza por la demanda y la respuesta parental llevadas a un grado extremo (Schaefer, 1997). Adicionalmente, esta clasificación no representa adecuadamente el tipo autoritativo, descripto como el equilibrio óptimo entre comportamientos de respuesta y de demanda (Baumrind, 1966, 1971, 1991a). De esta manera, la categorización proveniente de la combinación de la propuesta de Maccoby y Martin (1983) junto con la de Schaefer (1997) aparece como la más abarcadora para el análisis de este constructo (Figura 1).

A la luz de sus posibles repercusiones en el ajuste psicológico de los individuos que atraviesan la crianza, la identificación de inconsistencias en los estilos parentales se ha erigido como línea de investigación complementaria en esta área, (Dwairy, 2007; Dwairy \& Achoui, 2006; Dwairy, Achoui, Abouserie \& Farah, 2006; Lamm \& Keller, 2007; Lee, Daniels \& Kissinger, 2006; Lengua, 2006). Estos trabajos se dirigen a analizar posibles inconsistencias entre los estilos característicos de ambos progenitores (interparental) y en el ejercido por cada uno de ellos a lo largo del tiempo (intraparental). La hipótesis que se baraja postula que con independencia del estilo predominante, las inconsistencias resultan 
perjudiciales (Benson, Buehler \& Gerard, 2008; Lengua \& Kovacs, 2005; Tildesley \& Andrews, 2008).

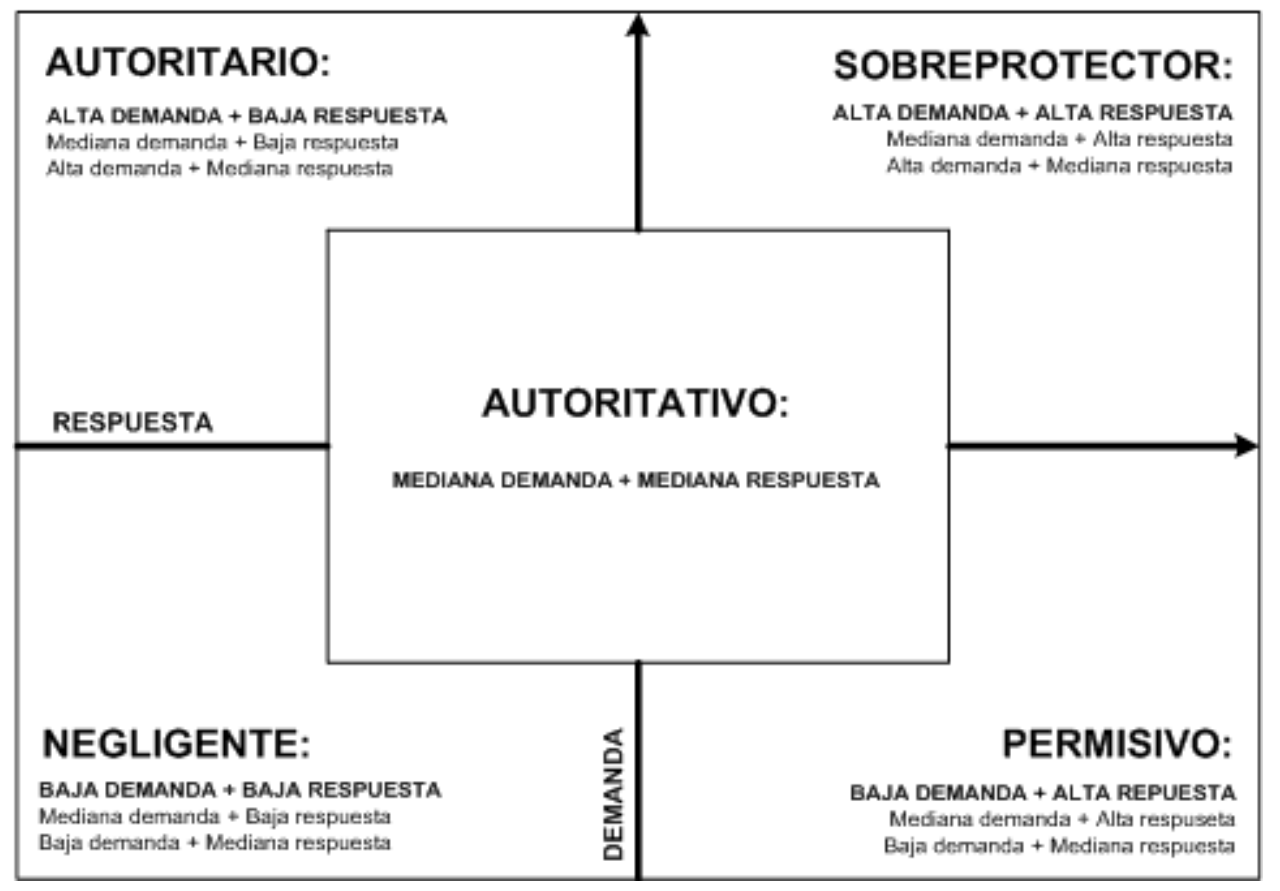

Figura 1. Tipología de cinco estilos parentales (Maccoby \& Martin, 1983; Schaefer, 1997).

\subsection{Medición de los estilos parentales percibidos}

Dentro del enfoque por dimensiones pueden localizarse varios instrumentos diseñados para evaluar el constructo operacionalizado en esa línea. Por caso, el Cuestionario de Aceptación-Rechazo Parental (PARQ, Rohner, Saavedra \& Granum, 1978) indaga sobre la dimensión de respuesta (o afectividad), proponiendo cuatro subescalas: percepción de calidez $\mathrm{y}$ aceptación, percepción de hostilidad y agresividad, percepción de indiferencia $\mathrm{y}$ negligencia, y percepción de rechazo indiferenciado.

El Children's Report of Parental Behavior (CRPB, Schaefer, 1965) considera tres bipolaridades continuas desglosadas en 26 scalas: aceptación vs. rechazo, autonomía psicológica vs. control psicológico, control firme vs. control laxo. Sus adaptaciones locales para niños de 4 a 6 años (Richaud de Minzi, 2002) y para adolescentes de 13 a 17 (Richaud de Minzi, 2005) reproducen estructuras factoriales similares a las propuestas por Schaefer (1965). Otra versión de la escala, dirigida a niños de 8 a 12 años (Richaud de Minzi, 2007) diferencia cinco estilos de relación parental: aceptación, control aceptado, control estricto, 
control patológico y autonomía extrema.

Evaluando la dimensión de demanda (o control) se destaca la Escala de Autoridad e Inconsistencia Parental (DPAIS, Dwairy, 2007), en la que se plantean situaciones de comportamiento adolescente de índole negativa y la potencial reacción de control o castigo por parte de los progenitores. Esta información se complementa indagando posibles inconsistencias en la reacción parental a lo largo del tiempo (inconsistencia intraparental).

La Escala de Socialización Parental para Adolescentes (ESPA-29, Musitu \& García, 2001) también propone una perspectiva situacional, presentando comportamientos negativos o positivos, apareados con una posible reacción parental distribuida en siete subescalas: afecto, indiferencia, diálogo, disciplicencia, coerción verbal, coerción física y privación. Ellas se agrupan en los dos ejes de socialización mencionados anteriormente, en este caso etiquetados como implicación/aceptación y coerción/imposición. Los autores proponen utilizar los resultados para evaluar los estilos parentales según la tipología tetracategorial formulada por Maccoby y Martin (1983).

De los instrumentos mencionados, el CRPB se encuentra dirigido a población infantil y adaptado en Argentina para niños y adolescentes (Richaud de Minzi, 2002, 2005, 2007; Schaefer, 1965); la DPAIS (Dwairy, 2007) y la ESPA-29 (Musitu \& García, 2001) se destinan a adolescentes. La PARQ posee versiones para niños, adultos y padres, aunque sólo contempla la dimensión de respuesta omitiendo la percepción de demanda parental.

Esta situación señala la necesidad de contar con escalas que tomen en cuenta ambas dimensiones del constructo y que posean adecuadas propiedades psicométricas para su aplicación en la población local de adultos jóvenes puesto que, como fue señalado, aún en esta etapa del ciclo vital los estilos de crianza continúan produciendo repercusiones (Anisman, Zaharia, Meaney \& Merali, 1998; Maccoby 1994; Rohner \& Veneziano 2001; Rothrauff, Cooney \& An 2009). De este modo, el objetivo de este trabajo es evaluar las propiedades psicométricas de la escala de Estilos Parentales e Inconsistencia Parental Percibida (EPIPP), con el fin de brindar un instrumento de evaluación psicológica que resulte de utilidad para su uso en los ámbitos de aplicación y de investigación.

\section{Método}

\subsection{Participantes.}

Se trabajó con una muestra no probabilística constituida por 373 estudiantes 
universitarios de la Ciudad de Buenos Aires (82,5\% mujeres, 17,5\% varones) con edades entre los 19 y los 35 años $(M=23,67$; $D E=2,75)$. El 96,2\% correspondía a estudiantes de la Universidad de Buenos Aires y el 3,8\%, a instituciones privadas de educación superior (Psicología 57,6\%, Nutrición 27,1\%, Ingeniería Electrónica 6,4\% y Traductorado Público de Inglés 5,4\%; otras carreras 3,5\%).

\subsection{Instrumentos.}

Se administró una encuesta sobre datos sociodemográficos y académicos conjuntamente con la escala de Estilos Parentales e Inconsistencia Parental Percibida (EPIPP), diseñada sobre la base de la ESPA-29 (Musitu \& García, 2001) y de la la DPAIS (Dwairy, 2007). Vale aclarar que la ESPA-29 evalúa las dimensiones de respuesta y demanda (a su vez compuestas por subdimensiones), y la DPAIS sólo la de demanda, aunque contempla la inconsistencia intraparental.

La EPPIP es un inventario autoadministrable para la evaluación de estilos parentales e inconsistencia parental percibida dirigido a adultos jóvenes. Transformando la puntuación directa a percentil, el usuario podrá valorar el grado de presencia de ambos aspectos del constructo (escalas de respuesta y demanda), identificando mediante su combinación, el estilo parental característico de cada progenitor (ver Anexo). Ello permitirá apreciar la posible inconsistencia interparental en el caso de que padre y madre exhiban estilos diferentes. También se podrá analizar la frecuencia de las prácticas contempladas en cada subescala. Finalmente, la escala posibilitará considerar el grado de inconsistencia intraparental.

\subsection{Procedimiento}

\subsubsection{Formulación de los items.}

Se utilizaron como ítems iniciales las circunstancias de socialización propuestas por la ESPA-29 (Musitu \& García, 2001) y la DPAIS (Dwairy, 2007), previa traducción de esta última. Éstas estaban redactadas en presente, indagando sobre vivencias actuales de adolescentes, debiendo ser reformuladas en pretérito con el fin de que los adultos jóvenes se remitieran a la socialización por ellos vivenciada durante su infancia y adolescencia. A las 39 situaciones planteadas en conjunto por ambos instrumentos se agregaron otras 18 con el fin de incluir escenarios característicos de la población objetivo, teniendo en cuenta también la necesidad de contar con una mayor cantidad de reactivos para llevar a cabo una adecuada depuración. Se consiguió así una versión de 57 eventos que fueron apareados con alguna 
posible reacción parental (e.g. "Mi padre/madre me lo agradecía, si lo/a ayudaba a lavar los platos”). Estas últimas correspondían a siete subescalas propuestas por los autores de la ESPA-29: afecto, diálogo, indiferencia, displicencia, coerción verbal, coerción física y prohibiciones (privación en la versión original).

La consigna indicaba que las respuestas debían referirse al padre y a la madre (construyéndose así las versiones PADRE y MADRE) o a otras personas que, según el criterio del evaluado, hubiesen cumplido esa función. Esto constituyó la "parte a" del instrumento, que posee un formato de respuesta likert de 4 opciones, redactado en términos de frecuencia temporal referida a la reacción parental indicada: Nunca, Algunas veces, Muchas veces y Siempre. El ordenamiento de puntuaciones de los ítems formulados originalmente en sentido negativo (indiferencia y displicencia) fue invertido para respetar el sentido positivo del resto de los elementos.

Cada reactivo se complementó con una "parte e", en la que se indagó si ante idénticas circunstancias la reacción del agente socializador era la misma. Este apartado asumió un formato de respuesta nominal dicotómica (Sí-No), ya que su propósito era medir la posible inconsistencia intraparental en el estilo de crianza. La inconsistencia interparental sería evaluada mediante la comparación del estilo para cada progenitor mediante las respuestas a la parte $a$ en las versiones PADRE y MADRE. En el Anexo se presentan la escala en su versión final y el perfil, para que el usuario pueda hacer los cálculos de puntuaciones.

\subsubsection{Recolección de datos y análisis de datos.}

Las administraciones fueron colectivas y estuvieron a cargo de psicólogos entrenados. Se solicitó un consentimiento informado para la participación, asegurándose la confidencialidad de los datos y facilitándose la posibilidad de una devolución individual de los resultados obtenidos en caso de ser solicitada. Los participantes fueron advertidos sobre la factibilidad de dejar de responder en el momento en que lo consideraran conveniente.

Esta versión preliminar fue sometida a juicio experto, estudio piloto y administrada a la muestra descripta con miras a analizar el poder discriminativo de los ítems, identificar una estructura factorial de primer orden que incluyera las subdimensiones propuestas por Musitu y Garcia (2001) y una de segundo orden que agrupara tales subdimensiones en dos factores cardinales (respuesta y demanda). Por último, se buscó examinar la consistencia y la estabilidad temporal de las mediciones logradas por escalas y subescalas. 


\section{Resultados}

\subsection{Juicio experto y aspectos formales.}

Los reactivos fueron sometidos a la valoración de cinco jueces argentinos expertos en el tema, que criticaron su contenido, la consigna de administración y el formato en general. Para analizar la pertenencia de los ítems a las respectivas dimensiones se calcularon coeficientes Aiken, estableciéndose un piso de .80 para aceptar cada elemento. Los 57 ítems iniciales fueron conservados. Algunas sugerencias sobre la redacción de elementos y consignas posibilitaron reformulaciones menores.

\subsection{Estudio piloto.}

Posteriormente se realizó un estudio piloto con 20 estudiantes universitarios, quienes aportaron sus opiniones para mejorar el formato y el contenido denotativo y connotativo de las afirmaciones. Estas modificaciones recibieron especial atención puesto que los reactivos tomados de la ESPA-29 y de la DPAIS estaban originalmente dirigidos a adolescentes, en tanto que en este caso se trabajaría con adultos jóvenes. Entre los cambios se destaca el realizado en el tiempo verbal, desde el pretérito imperfecto del indicativo al pretérito pluscuamperfecto del subjuntivo. Ello se debió a que algunas de las situaciones planteadas no habían sido vivenciadas por los estudiantes (algo razonable debido a la imposibilidad de identificar e incluir todas las circunstancias de socialización posibles) o resultaban incómodas para responderse en un ámbito educativo, a pesar de la confidencialidad de los datos (ej.: "Mi padre/madre se sentaba a hablar del tema conmigo, si usaba drogas y se enteraban de ello", pasó a ser: "Mi padre/madre se hubiese sentado a hablar del tema conmigo si hubiese usado drogas, y se hubiese enterado de ello"). El resto de las alteraciones revistió un carácter menor.

\subsection{Análisis de items: Discriminación y homogeneidad.}

Se evaluó la capacidad discriminativa de los ítems para las versiones PADRE y MADRE, suprimiéndose aquellos con frecuencias mayores al 75\% en alguna opción de respuesta. También se examinó la normalidad univariante mediante los estadísticos de contraste $(\mathrm{zG})$ para los valores de asimetría y curtosis con sus correspondientes errores típicos, esperando que no superaran los guarismos de $\pm 1,96$ (Lévy Mangin \& Varela Mallou, 2006). 
Tabla 1.

EPIPP, versiones Padre: Descriptivos para los ítems.

\begin{tabular}{|c|c|c|c|c|c|c|c|c|}
\hline \multirow[b]{2}{*}{ Subescala } & \multirow[b]{2}{*}{ Media(D.E.) } & \multicolumn{3}{|c|}{ Asimetría } & \multicolumn{4}{|c|}{ Curtosis } \\
\hline & & Estadístico & $\begin{array}{l}\text { Error } \\
\text { Típico } \\
\end{array}$ & $\mathbf{z}\left(\mathbf{G}_{1}\right)$ & Estadístico & $\begin{array}{l}\text { Error } \\
\text { Típico } \\
\end{array}$ & $\mathbf{z}\left(\mathbf{G}_{2}\right)$ & IHc \\
\hline \multicolumn{9}{|l|}{ Afecto } \\
\hline Ítem 42 & $3.17(.85)$ & -.625 & .129 & -4.844 & -.644 & .256 & -2.515 & .458 \\
\hline Ítem 45 & $3.45(.84)$ & -1.312 & .129 & 10.170 & .542 & .256 & 2.117 & .462 \\
\hline Ítem 47 & $2.14(1.01)$ & .586 & .129 & 4.542 & -.719 & .257 & -2.797 & .530 \\
\hline Ítem 49 & $2.36(1.05)$ & .277 & .129 & 2.147 & -1.120 & .256 & -4.375 & .590 \\
\hline Ítem 55 & $2.68(1.08)$ & -.141 & .129 & -1.093 & -1.288 & .256 & -5.031 & .560 \\
\hline \multicolumn{9}{|l|}{ Diálogo } \\
\hline Ítem 2 & $2.55(1.06)$ & .062 & .129 & .480 & -1.238 & .257 & -4.817 & .443 \\
\hline Ítem 9 & $2.74(1.00)$ & -.083 & .129 & -.643 & -1.202 & .257 & -4.677 & .442 \\
\hline Ítem 20 & $2.87(1.08)$ & -.361 & .129 & -2.798 & -1.252 & .257 & -4.871 & .574 \\
\hline Ítem 34 & $2.83(1.03)$ & -.240 & .129 & -1.860 & -1.216 & .257 & -4.731 & .442 \\
\hline \multicolumn{9}{|l|}{ Indiferencia } \\
\hline Ítem 35 & $3.49(.88)$ & -1.752 & .129 & -13.581 & 2.051 & .257 & 7.980 & .358 \\
\hline Ítem 38 & $3.43(.87)$ & -1.526 & .129 & -11.829 & 1.441 & .257 & 5.607 & .403 \\
\hline Ítem 43 & $3.45(.96)$ & -1.629 & .129 & -12.627 & 1.285 & .257 & 5.000 & .316 \\
\hline Ítem 56 & $3.39(.93)$ & -1.425 & .129 & -11.046 & .875 & .257 & 3.334 & .334 \\
\hline \multicolumn{9}{|c|}{ Coerción verbal } \\
\hline Ítem 13 & $1.83(.90)$ & .823 & .129 & 6.379 & -.253 & .257 & -.984 & .366 \\
\hline Ítem 15 & $1.76(.84)$ & 1.000 & .129 & 7.751 & .386 & .257 & 1.501 & .441 \\
\hline Ítem 41 & $2.39(.93)$ & .295 & .129 & 2.286 & -.779 & .257 & 3.031 & .512 \\
\hline Ítem 46 & $2.64(.90)$ & .118 & .129 & 0.914 & -.930 & .257 & 3.618 & .432 \\
\hline \multicolumn{9}{|c|}{ Coerción Física } \\
\hline Ítem 10 & $1.57(.93)$ & 1.571 & .129 & 12.178 & 1.314 & .257 & 9.267 & .604 \\
\hline Ítem 27 & $1.23(.55)$ & 2.706 & .129 & 20.976 & 7.811 & .257 & 30.392 & .630 \\
\hline Ítem 40 & $1.25(.59)$ & 2.654 & .129 & 20.573 & 7.023 & .257 & 27.326 & .618 \\
\hline \multicolumn{9}{|l|}{ Prohibición } \\
\hline Ítem 12 & $2.31(1.16)$ & .322 & .129 & 2.496 & -1.370 & .257 & -5.330 & .413 \\
\hline Ítem 22 & $1.81(.94)$ & .869 & .129 & 6.736 & -.355 & .257 & -1.281 & .436 \\
\hline Ítem 31 & $1.86(.97)$ & .917 & .129 & 7.108 & -.199 & .257 & -0.774 & .412 \\
\hline Ítem 33 & $1.67(.84)$ & 1.205 & .129 & 9.341 & .788 & .257 & 3.066 & .497 \\
\hline
\end{tabular}

Finalmente, se calcularon índices de homogeneidad corregidos (IHc) por subescala, eliminándose las formulaciones con valores inferiores a .30 (Martínez Arias, 1995). La mayoría de los elementos no cumplía con los criterios de normalidad univariante, algo esperado de acuerdo con la naturaleza ordinal de los datos. Los elementos de la subescala displicencia mostraban IHc inferiores a lo deseados. Ninguno de los ítems de coerción física (ej: "Mi padre/madre me hubiese golpeado, si lo/a hubiese insultado") cumplía con los criterios de frecuencia esperados; sin embargo, se decidió conservar ambas subescalas para observar su comportamiento factorial en virtud de la importancia de evaluar la presencia de coerción física cuando se miden estilos parentales percibidos (Baumrind, 1994, 1996b; 
Baumrind, Larzelere \& Cowan, 2002). Las Tablas 1 y 2 resumen los estadísticos descriptivos de los ítems componentes de la versión final.

Tabla 2.

EPIPP, versión Madre: Descriptivos para los ítems.

\begin{tabular}{|c|c|c|c|c|c|c|c|c|}
\hline \multirow[b]{2}{*}{ Subescala } & \multirow[b]{2}{*}{ Media(D.E.) } & \multicolumn{3}{|c|}{ Asimetría } & \multicolumn{4}{|c|}{ Curtosis } \\
\hline & & Estadístico & $\begin{array}{l}\text { Error } \\
\text { Típico }\end{array}$ & $\mathbf{z}\left(\mathbf{G}_{1}\right)$ & Estadístico & $\begin{array}{l}\text { Error } \\
\text { Típico }\end{array}$ & $\mathbf{z}\left(\mathbf{G}_{2}\right)$ & IHc \\
\hline \multicolumn{9}{|l|}{ Afecto } \\
\hline Ítem 45 & $3.56(.73)$ & -1.581 & .129 & -12.255 & 1.729 & .257 & 6.727 & .383 \\
\hline Ítem 47 & $2.26(1.01)$ & .382 & .129 & 2.961 & -.920 & .257 & -3.579 & .470 \\
\hline Ítem 49 & $2.85(1.03)$ & -.283 & .129 & -2.170 & -1.158 & .257 & -4.505 & .498 \\
\hline Ítem 55 & $2.89(1.02)$ & -.387 & .129 & -3.000 & -1.057 & .257 & -4.112 & .495 \\
\hline \multicolumn{9}{|l|}{ Diálogo } \\
\hline Ítem 2 & 2.99(.94) & -.522 & .129 & -4.046 & .770 & .257 & 2.996 & .403 \\
\hline Ítem 9 & $2.90(.92)$ & -.244 & .129 & -1.891 & -1.037 & .257 & -4.035 & .454 \\
\hline Ítem 20 & $3.08(.96)$ & -.585 & .129 & -4.534 & -.916 & .257 & -3.564 & .503 \\
\hline Ítem 34 & $3.07(.92)$ & -.505 & .129 & -3.914 & -.878 & .257 & -3.416 & .394 \\
\hline \multicolumn{9}{|c|}{ Indiferencia } \\
\hline Ítem 35 & $3.44(.94)$ & -1.512 & .129 & -11.720 & .954 & 257 & 3.712 & .318 \\
\hline Ítem 38 & $3.38(.89)$ & -1.347 & .129 & -10.441 & .874 & .257 & 3.400 & .365 \\
\hline Ítem 43 & $3.42(1.02)$ & -1.505 & .129 & -11.666 & .723 & .257 & 2.813 & .315 \\
\hline Ítem 56 & $3.35(.97)$ & -1.318 & .129 & -10.217 & .469 & .257 & 1.824 & .341 \\
\hline \multicolumn{9}{|c|}{ Coerción verbal } \\
\hline Ítem 13 & 1.99(.95) & .586 & .129 & 4.614 & -.676 & .257 & -2.630 & .396 \\
\hline Ítem 15 & $2.54(.94)$ & .005 & .129 & 0.038 & .906 & .257 & 3.525 & .531 \\
\hline Ítem 41 & $2.92(.87)$ & -.134 & .129 & -1.038 & -1.094 & 257 & -4.256 & .512 \\
\hline Ítem 46 & $2.77(.88)$ & -.016 & .129 & -0.124 & -.931 & .257 & -3.622 & .399 \\
\hline \multicolumn{9}{|c|}{ Coerción Física } \\
\hline Ítem 10 & 1.63(.93) & 1.403 & .129 & 10.875 & .876 & .257 & 3.408 & .534 \\
\hline Ítem 27 & $1.22(.51)$ & 2.599 & .129 & 20.147 & 7.217 & .257 & 28.081 & .478 \\
\hline Ítem 40 & $1.27(.59)$ & 2.515 & .129 & 19.496 & 6.790 & .257 & 26.420 & .522 \\
\hline \multicolumn{9}{|l|}{ Prohibición } \\
\hline Ítem 12 & $2.42(1.17)$ & .123 & .129 & 0.953 & -1.459 & .257 & -5.677 & 430 \\
\hline Ítem 22 & $2.03(1.06)$ & .646 & .129 & 0.083 & -.851 & 257 & -3.311 & .478 \\
\hline Ítem 31 & $1.96(.98)$ & .776 & .129 & 6.015 & -.439 & .257 & -1.708 & .408 \\
\hline Ítem 33 & $1.80(.93)$ & 1.053 & .129 & 8.162 & .255 & .257 & 0.992 & .487 \\
\hline
\end{tabular}

\subsection{Estudio factorial exploratorio de primer orden.}

Los 57 reactivos fueron sometidos a un estudio factorial exploratorio en el que se utilizó la matriz de rango de Spearman por contemplar la índole ordinal de las variables incluidas. Dado que los valores perdidos se distribuían al azar y se registraban en porcentuales que se encontraban muy por debajo de 30, se los excluyó según lista (Varela Mallou, Rojas Tejada \& Rial Boubeta, 2001). Para que los resultados reflejaran la varianza total (y no sólo la común, dejando fuera la específica y la de error) se utilizó el análisis de 
componentes principales (Hair, Anderson, Tathan \& Black, 1999). La rotación seleccionada fue Varimax debido a que las asociaciones entre las escalas no eran elevadas (ver Tabla 3).

Tabla 3.

EPIPP, versiones Padre y Madre: Correlaciones entre las subescalas.

\begin{tabular}{|c|c|c|c|c|c|c|}
\hline & Afecto & Diálogo & Indiferencia & $\begin{array}{c}\text { Coerción } \\
\text { verbal }\end{array}$ & $\begin{array}{c}\text { Coerción } \\
\text { física } \\
\end{array}$ & Prohibiciones \\
\hline \multicolumn{7}{|l|}{ Versión PADRE } \\
\hline Afecto & 1 & & & & & \\
\hline Diálogo & $.482^{* *}$ & 1 & & & & \\
\hline Indiferencia & $.281^{* *}$ & $.206^{* *}$ & 1 & & & \\
\hline Coerción verbal & $.126^{*}$ & $.186^{* *}$ & .042 & 1 & & \\
\hline Coerción física & -.047 & -.023 & -.096 & $.139^{* *}$ & 1 & \\
\hline Prohibiciones & $.195^{* *}$ & $.219^{* *}$ & -.098 & $.393^{* *}$ & $.326^{* *}$ & 1 \\
\hline \multicolumn{7}{|l|}{ Versión MADRE } \\
\hline Afecto & 1 & & & & & \\
\hline Diálogo & $.381^{* *}$ & 1 & & & & \\
\hline Indiferencia & $.252^{* *}$ & $.183^{* *}$ & 1 & & & \\
\hline Coerción verbal & $.104^{*}$ & $.192^{* *}$ & .007 & 1 & & \\
\hline Coerción física & -.033 & .025 & $-.151^{* *}$ & $.240^{* *}$ & 1 & \\
\hline Prohibiciones & $.155^{* *}$ & $207^{* *}$ & $-.121^{*}$ & $.427^{* *}$ & $.262^{* *}$ & 1 \\
\hline
\end{tabular}
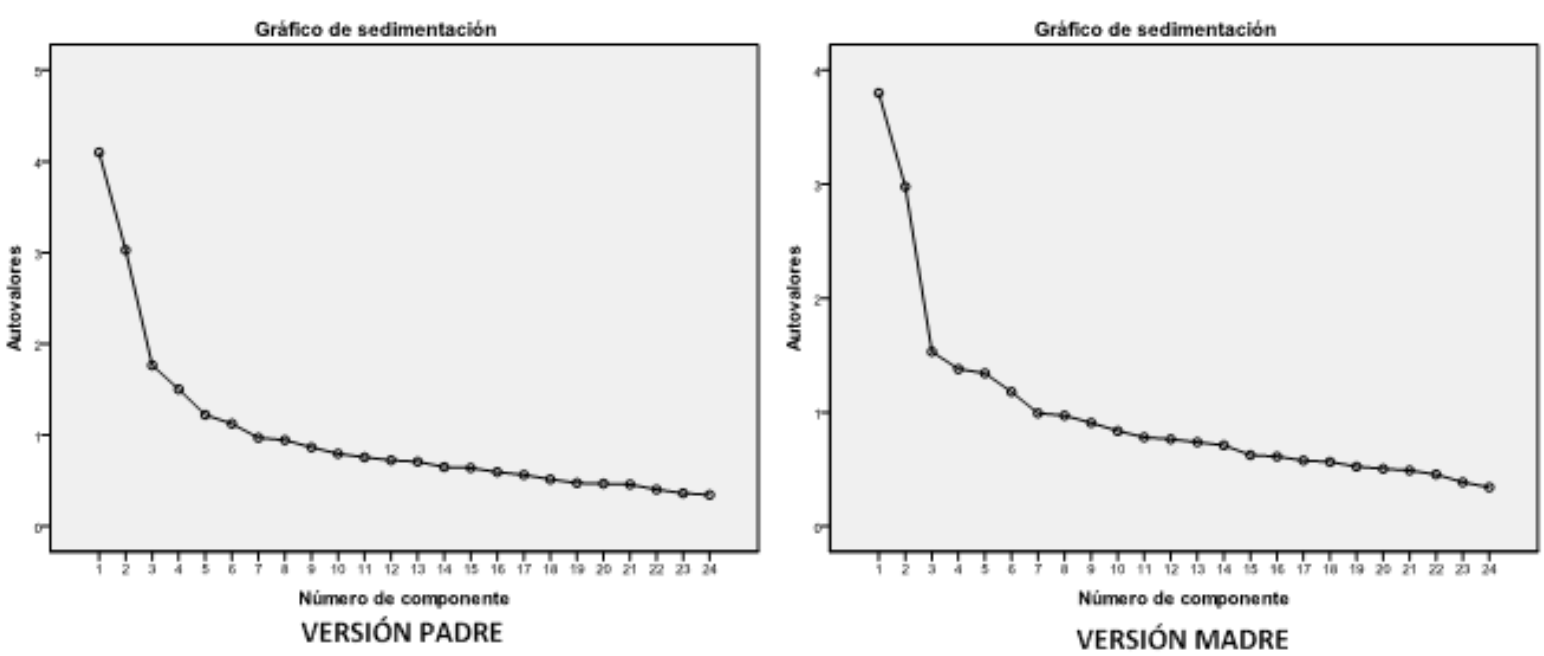

Figura 2. Gráficos de sedimentación para las versiones PADRE y MADRE.

En primera instancia se evaluaron los gráficos de sedimentación correspondientes a ambas versiones para determinar el número de factores a ser aislados; se apreciaba un cambio de pendiente a partir del sexto factor (Figura 2). De todos modos, dado que el modelo contemplaba siete subdimensiones (Musitu \& García, 2001), y uno de los propósitos de este 
estudio era la replicación de tal estructura, con fines comparativos se forzó la extracción de siete factores. Tal como indicaba el gráfico de sedimentación y teniendo en consideración que sólo las primeras seis variables latentes exhibían autovalores mayores que uno, una estructura heptadimensional no era la adecuada. La subescala displicencia no se diferenciaba del resto y sus elementos no correlacionaban con ninguna de las otras subescalas. Extrayendo seis factores se logró aislar estructuras factoriales idénticas para las versiones PADRE $\left(\chi^{2}=\right.$ $1.966,818 ; g . l .=276 ; p<.0001 ; \mathrm{KMO}=.785)$ y $\operatorname{MADRE}\left(\chi^{2}=1.636,715 ; g . l .=276 ; p<.0001\right.$; $\mathrm{KMO}=.759)$. Los 24 reactivos que componían cada versión mostraban cargas superiores a . 45 en un único factor. Las soluciones explicaban el 52,98\% y el 50,13\% de la varianza total, respectivamente. La varianza explicada por cada factor se distribuyó en forma equitativa (ver Tablas 4 y 5).

Tabla 4.

EPIPP, versión Padre: Estructura factorial

\begin{tabular}{|c|c|c|c|c|c|c|}
\hline & \multicolumn{6}{|c|}{ Factores } \\
\hline & 1 & 2 & 3 & 4 & 5 & 6 \\
\hline Ítem 42 Padre & .546 & & & & & \\
\hline Ítem 45 Padre & .508 & & & & & \\
\hline Ítem 47 Padre & .723 & & & & & \\
\hline Ítem 49 Padre & .741 & & & & & \\
\hline Ítem 55 Padre & .694 & & & & & \\
\hline Ítem 2 Padre & & & & & .661 & \\
\hline Ítem 9 Padre & & & & & .743 & \\
\hline Ítem 20 Padre & & & & & .753 & \\
\hline Ítem 34 Padre & & & & & .454 & \\
\hline Ítem 35 Padre & & & & .626 & & \\
\hline Ítem 38 Padre & & & & .654 & & \\
\hline Ítem 43 Padre & & & & .666 & & \\
\hline Ítem 56 Padre & & & & .627 & & \\
\hline Ítem 13 Padre & & .470 & & & & \\
\hline Ítem 15 Padre & & .679 & & & & \\
\hline Ítem 41 Padre & & .736 & & & & \\
\hline Ítem 46 Padre & & .688 & & & & \\
\hline Ítem 10 Padre & & & .785 & & & \\
\hline Ítem 27 Padre & & & .800 & & & \\
\hline Ítem 40 Padre & & & .828 & & & \\
\hline Ítem 12 Padre & & & & & & .633 \\
\hline Ítem 22 Padre & & & & & & .696 \\
\hline Ítem 31 Padre & & & & & & .580 \\
\hline Ítem 33 Padre & & & & & & .702 \\
\hline $\begin{array}{l}\text { \%varianza } \\
\text { explicada }\end{array}$ & 10,646 & 8,343 & 8,711 & 8,034 & 8,451 & 8,802 \\
\hline
\end{tabular}


Tabla 5.

EPIPP, versión Madre: Estructura factorial

\begin{tabular}{|c|c|c|c|c|c|c|}
\hline & \multicolumn{6}{|c|}{ Factor } \\
\hline & 1 & 2 & 3 & 4 & 5 & 6 \\
\hline Ítem 42 Madre & & .570 & & & & \\
\hline Ítem 45 Madre & & .456 & & & & \\
\hline Ítem 47 Madre & & .687 & & & & \\
\hline Ítem 49 Madre & & .760 & & & & \\
\hline Ítem 55 Madre & & .657 & & & & \\
\hline Ítem 2 Madre & & & & & .626 & \\
\hline Ítem 9 Madre & & & & & .700 & \\
\hline Ítem 20 Madre & & & & & .758 & \\
\hline Ítem 34 Madre & & & & & .549 & \\
\hline Ítem 35 Madre & & & & .655 & & \\
\hline Ítem 38 Madre & & & & .547 & & \\
\hline Ítem 43 Madre & & & & .655 & & \\
\hline Ítem 56 Madre & & & & .659 & & \\
\hline Ítem 13 Madre & .568 & & & & & \\
\hline Ítem 15 Madre & .783 & & & & & \\
\hline Ítem 41 Madre & .754 & & & & & \\
\hline Ítem 46 Madre & .525 & & & & & \\
\hline Ítem 10 Madre & & & .744 & & & \\
\hline Ítem 27 Madre & & & .727 & & & \\
\hline Ítem 40 Madre & & & .762 & & & \\
\hline Ítem 12 Madre & & & & & & .629 \\
\hline Ítem 22 Madre & & & & & & .723 \\
\hline Ítem 31 Madre & & & & & & .585 \\
\hline Ítem 33 Madre & & & & & & .712 \\
\hline$\%$ varianza explicada & 8,615 & 9,108 & 7,533 & 7,835 & 8,333 & 8,707 \\
\hline
\end{tabular}

\subsection{Estudio factorial exploratorio de segundo orden.}

Intentando verificar que las subescalas reportaran a las dos dimensiones propuestas como cardinales en la medición de las prácticas parentales -demanda y respuesta-, se realizó un estudio factorial de segundo orden usando como input las sumatorias de los ítems en cada dimensión correspondiente al análisis de primer orden, tanto para la versión PADRE cuanto para la versión MADRE. En esta ocasión se utilizó la matriz de correlaciones de Pearson. Mediante sendos análisis de componentes principales con rotación Varimax y normalización Kaiser, forzando a dos factores se halló la estructura buscada, identificándose dos variables latentes denominadas respuesta y demanda, idénticas en ambas versiones (Versión PADRE: $\mathrm{KMO}=.607$; Test de Esfericidad de Bartlett: $\chi^{2}=274,168 ;$ g.l. $=15 ; p<.0001$; Versión MADRE: $\mathrm{KMO}=.630$; Test de Esfericidad de Bartlett; $\chi^{2}=252,175 ;$ g.l. $=15 ; \mathrm{p}<.0001$; ver Tabla 6). 
Tabla 6.

EPIPP, versiones Padre y Madre: Estructuras factoriales de segundo orden.

\begin{tabular}{|c|c|c|c|c|}
\hline & \multicolumn{2}{|c|}{ EPIPP-PADRE Factores } & \multicolumn{2}{|c|}{ EPIPP-MADRE Factores } \\
\hline & 1 & 2 & 1 & 2 \\
\hline Afecto & .797 & & & .772 \\
\hline Diálogo & .759 & & & .714 \\
\hline Indiferencia & .630 & & & .630 \\
\hline Coerción verbal & & .654 & .737 & \\
\hline Coerción física & & .641 & .639 & \\
\hline Prohibiciones & & .822 & .776 & \\
\hline $\begin{array}{ll}\% & \text { varianza } \\
\text { explicada } & \\
\end{array}$ & 28,852 & 27,777 & 29,158 & 26,804 \\
\hline $\begin{array}{l}\% \text { varianza total } \\
\text { explicada: }\end{array}$ & 56 & & & \\
\hline
\end{tabular}

\subsection{Consistencia de las dimensiones.}

Luego de someter los ítems nuevamente a estudios de homogeneidad, evaluándose los IHc según cada subescala (compuesta ahora por menos reactivos), se calcularon Alfas de Cronbach para valorar su consistencia interna, verificándose buenos índices en la mayoría, con excepción de la subescala indiferencia cuyos valores fueron menores, aunque aceptables (ver Tabla 7). A su vez, se calcularon Alfas ordinales para cada subescala tomando en consideración las características categóricas ordenadas de las respuestas, observándose mejoras en todos los casos (Elosúa \& Zumbo, 2008).

Tabla 7.

EPIPP, versiones Padre y Madre: Alfas de Cronbach.

\begin{tabular}{lccccc}
\hline & \multicolumn{2}{c}{ EPIPP-PADRE } & & \multicolumn{2}{c}{ EPIPP-MADRE } \\
\cline { 2 - 3 } \cline { 5 - 6 } Subescala & $\begin{array}{c}\text { Alfa de } \\
\text { Cronbach }\end{array}$ & Alfa ordinal & & $\begin{array}{c}\text { Alfa de } \\
\text { Cronbach }\end{array}$ & Alfa ordinal \\
\hline Afecto & .753 & .776 & & .694 & .761 \\
Diálogo & .691 & .744 & & .658 & .752 \\
Indiferencia & .569 & .738 & & .549 & .723 \\
Coerción verbal & .656 & .735 & & .676 & .749 \\
Coerción Física & .749 & .846 & & .662 & .788 \\
Prohibición & .652 & .747 & & .666 & .756 \\
\hline
\end{tabular}

\subsection{Estabilidad de las puntuaciones.}

Para analizar la estabilidad de las puntuaciones se realizó un estudio test-retest con 18 estudiantes de Psicología de la Universidad de Buenos Aires (21 a 26 años; $\mathrm{M}_{\text {edad }}=22$; D.E. = 1,41). El intervalo entre las evaluaciones fue de dos meses y medio. Las correlaciones de Pearson calculadas resultaron aceptables a buenas, excepto las de la subescala indiferencia de 
la versión PADRE (Tabla 8).

Tabla 8.

EPIPP, versiones Padre y Madre: Estabilidad temporal

\begin{tabular}{lcc}
\hline & $(\mathbf{r})$ PADRE & $(\mathbf{r})$ MADRE \\
\cline { 2 - 3 } Subescala & & \\
Afecto & $.731^{* *}$ & $.750^{* *}$ \\
Diálogo & $.888^{* *}$ & $.863^{* *}$ \\
Indiferencia & .254 & $.526^{*}$ \\
Coerción Verbal & $.802^{* *}$ & $.860^{* *}$ \\
Coerción Física & $.774^{* *}$ & $.895^{* *}$ \\
Prohibición & $.852^{* *}$ & $.916^{* *}$ \\
Escalas & & \\
Respuesta & $.521^{*}$ & $.646^{* *}$ \\
Demanda & $.844^{* *}$ & $.915^{* *}$ \\
Inconsistencia Intraparental & $.866^{* *}$ & $.717^{* *}$ \\
\hline
\end{tabular}

Tabla 9.

Baremo para adultos jóvenes universitarios de la Ciudad Autónoma de Buenos Aires: Escalas.

\begin{tabular}{|c|c|c|c|c|c|c|}
\hline & \multicolumn{3}{|c|}{ Padre } & \multicolumn{3}{|c|}{ Madre } \\
\hline & Respuesta & Demanda & $\begin{array}{l}\text { Inconsistencia } \\
\text { Intraparental }\end{array}$ & Respuesta & Demanda & $\begin{array}{l}\text { Inconsistencia } \\
\text { Intraparental }\end{array}$ \\
\hline $\mathbf{N}$ & 363 & 363 & 363 & 370 & 370 & 370 \\
\hline Media & 38,28 & 20,24 & 27,53 & 40,37 & 22,47 & 27,34 \\
\hline Mediana & 39,00 & 19,00 & 26,00 & 41,00 & 22,00 & 26,00 \\
\hline Moda & 39,00 & 19,00 & 24,00 & 41,00 & 21,00 & 24,00 \\
\hline $\begin{array}{l}\text { D. E. } \\
\text { Mínimo }\end{array}$ & $\begin{array}{c}7,01 \\
12,00\end{array}$ & $\begin{array}{c}5,22 \\
10,00\end{array}$ & $\begin{array}{c}4,68 \\
13,00\end{array}$ & $\begin{array}{c}6,36 \\
11,00\end{array}$ & $\begin{array}{c}5,47 \\
11,00\end{array}$ & $\begin{array}{c}4,45 \\
13,00\end{array}$ \\
\hline Máximo & 52,00 & 36,00 & 54,00 & 52,00 & 43,00 & 48,00 \\
\hline \multicolumn{7}{|c|}{ Percentiles } \\
\hline 1 & 17 & 11 & 22 & 21 & 12 & 22 \\
\hline 5 & 26 & 13 & 24 & 29 & 14 & 24 \\
\hline 10 & 29 & 14 & 24 & 32 & 16 & 24 \\
\hline 15 & 31 & 15 & 24 & 34 & 17 & 24 \\
\hline 20 & 33 & 16 & 24 & 36 & 18 & 24 \\
\hline 25 & 34 & 17 & 24 & 37 & 19 & 24 \\
\hline 30 & 35 & 17 & 25 & 38 & 19 & 25 \\
\hline 35 & 36 & 18 & 25 & 39 & 20 & 25 \\
\hline 40 & 37 & 18 & 25 & 39 & 21 & 25 \\
\hline 45 & 38 & 19 & 25 & 40 & 21 & 25 \\
\hline 50 & 39 & 19 & 26 & 41 & 22 & 26 \\
\hline 55 & 40 & 20 & 27 & 42 & 23 & 27 \\
\hline 60 & 40 & 21 & 27 & 43 & 23 & 27 \\
\hline 65 & 41 & 22 & 28 & 43 & 24 & 27 \\
\hline 70 & 42 & 23 & 29 & 44 & 25 & 28 \\
\hline 75 & 43 & 24 & 30 & 45 & 26 & 29 \\
\hline 80 & 44 & 25 & 31 & 46 & 27 & 30 \\
\hline 85 & 45 & 26 & 32 & 47 & 28 & 31 \\
\hline 90 & 47 & 28 & 34 & 48 & 30 & 33 \\
\hline 95 & 49 & 30 & 37 & 50 & 32 & 36 \\
\hline 99 & 52 & 33 & 45 & 52 & 38 & 45 \\
\hline
\end{tabular}




\subsection{Baremización.}

Finalmente, se calcularon los percentiles para las puntuaciones directas de las escalas de respuesta y demanda, así como los correspondientes al cálculo de la inconsistencia intraparental por un lado (ver Tabla 9), y para las subescalas de las versiones PADRE y MADRE, por el otro (ver Tablas 10 y 11).

Tabla 10.

Baremo para adultos jóvenes universitarios de la Ciudad Autónoma de Buenos Aires: Subescalas (versión PADRE).

\begin{tabular}{ccccccc}
\hline & \multicolumn{6}{c}{ PADRE } \\
\cline { 2 - 7 } & Afecto & Diálogo & Indiferencia & $\begin{array}{c}\text { Coerción } \\
\text { Verbal }\end{array}$ & $\begin{array}{c}\text { Coerción } \\
\text { Física }\end{array}$ & Prohibiciones \\
\hline N & 360 & 363 & 363 & 363 & 363 & 363 \\
Media & 13,79 & 10,94 & 13,66 & 8,57 & 4,03 & 7,63 \\
Mediana & 14,00 & 11,00 & 14,00 & 8,00 & 3,00 & 7,00 \\
Moda & 14,00 & 12,00 & 16,00 & 7,00 & 3,00 & 5,00 \\
D.E. & 3,45 & 3,01 & 2,57 & 2,54 & 1,75 & 2,78 \\
Mínimo & 5,00 & 4,00 & 4,00 & 4,00 & 2,00 & 2,00 \\
Máximo & 20,00 & 16,00 & 16,00 & 16,00 & 12,00 & 16,00 \\
Percentiles & & & & & & \\
$\mathbf{1 0}$ & 9 & 7 & 10 & 5 & 3 & 4 \\
$\mathbf{2 0}$ & 11 & 8 & 12 & 6 & 3 & 5 \\
$\mathbf{3 0}$ & 12 & 9 & 13 & 7 & 3 & 6 \\
$\mathbf{4 0}$ & 13 & 10 & 14 & 8 & 3 & 7 \\
$\mathbf{5 0}$ & 14 & 11 & 14 & 8 & 3 & 8 \\
$\mathbf{6 0}$ & 14 & 12 & 15 & 9 & 3 & 9 \\
$\mathbf{7 0}$ & 16 & 13 & 16 & 10 & 4 & 10 \\
$\mathbf{8 0}$ & 17 & 14 & 16 & 11 & 5 & 12 \\
$\mathbf{9 0}$ & 18 & 15 & 16 & 12 & 7 & \\
\hline
\end{tabular}

\section{Discusión}

Las propiedades psicométricas de la EPIPP, diseñada especialmente con fines de investigación, fueron evaluadas mediante estudios que consideraron varios aspectos de interés. En primer término, se aportaron evidencias de validez aparente y se analizó su adecuación lingüística (administración piloto); en segundo término, se examinó la capacidad de discriminación de los ítems corregidos (cálculos de frecuencias, índices de homogeneidad, asimetría y curtosis); luego se avanzó en la búsqueda de evidencias de validez de contenido (juicio de expertos), de validez de constructo (estudios factoriales exploratorios de primer y segundo orden) y en el análisis de confiabilidad en cuanto a consistencia interna y a la estabilidad de las puntuaciones (Alfas de Cronbach y ordinales, y estudio test-retest). 
Tabla 11.

Baremo para adultos jóvenes universitarios de la Ciudad Autónoma de Buenos Aires: Subescalas (versión MADRE) 


\begin{tabular}{|c|c|c|c|c|c|c|}
\hline & \multicolumn{6}{|c|}{ Madre } \\
\hline & Afecto & Diálogo & Indiferencia & $\begin{array}{c}\text { Coerción } \\
\text { Verbal }\end{array}$ & $\begin{array}{c}\text { Coerción } \\
\text { Física }\end{array}$ & Prohibiciones \\
\hline $\mathbf{N}$ & 367 & 370 & 370 & 370 & 370 & 370 \\
\hline Media & 14,98 & 12,00 & 13,50 & 10,14 & 4,11 & 8,22 \\
\hline Mediana & 15,00 & 12,00 & 14,00 & 10,00 & 3,00 & 8,00 \\
\hline Moda & 15,00 & 12,00 & 16,00 & 10,00 & 3,00 & 8,00 \\
\hline D.E. & 3,058 & 2,65 & 2,65 & 2,66 & 1,63 & 2,96 \\
\hline Mínimo & 6,00 & 5,00 & 3,00 & 2,00 & 2,00 & 2,00 \\
\hline Máximo & 20,00 & 16,00 & 16,00 & 16,00 & 11,00 & 16,00 \\
\hline \multicolumn{7}{|l|}{ Percentiles } \\
\hline $\mathbf{1 0}$ & 11 & 8 & 10 & 7 & 3 & 5 \\
\hline 20 & 13 & 10 & 12 & 8 & 3 & 5 \\
\hline 30 & 14 & 11 & 13 & 9 & 3 & 6 \\
\hline 40 & 14 & 12 & 13 & 9 & 3 & 7 \\
\hline 50 & 15 & 12 & 14 & 10 & 3 & 8 \\
\hline 60 & 16 & 13 & 15 & 11 & 4 & 9 \\
\hline 70 & 17 & 14 & 16 & 12 & 4 & 9 \\
\hline 80 & 18 & 14 & 16 & 12 & 5 & 11 \\
\hline 90 & 19 & 15 & 16 & 13 & 6 & 13 \\
\hline
\end{tabular}

Los resultados muestran una excelente capacidad discriminativa de los reactivos, a excepción de la subescala coerción física. Ello podría deberse a la baja frecuencia de esta práctica parental en la muestra analizada o a un efecto de deseabilidad social que impide a los sujetos dar respuestas que indiquen el uso de este método de control.

Las evidencias de validez de constructo apoyan la línea teórica que subyace al modelo. El instrumento brinda datos sobre las dimensiones postuladas como fundamentales (demanda y respuesta), posibilitando, a la vez, un estudio al interior de cada factor, a través del análisis de sus correspondientes subescalas: afecto, diálogo, indiferencia, coerción verbal, coerción física y prohibición. Mediante la combinación de los puntajes obtenidos en las dimensiones demanda y respuesta se pueden describir los cinco estilos parentales (negligente, autoritario, permisivo, sobreprotector y autoritativo) lo que facilita un análisis según tipologías (Maccoby \& Martín, 1983; Schaefer, 1997). En este sentido, una de las fortalezas principales de este trabajo radica en el hecho de haber logrado aislar la misma estructura para la versión PADRE y para la versión MADRE. Ello permite el análisis de inconsistencias interparentales a través de la identificación del estilo característico de cada progenitor, resultante de la combinación de los puntajes obtenidos en las dos escalas principales. A su vez, es posible realizar inferencias sobre el grado de inconsistencia intraparental, es decir, sobre la variación de las reacciones del progenitor en el tiempo, que hace a la predictibilidad de los comportamientos parentales por parte de los hijos, teniendo un efecto directo como factor protector en el caso de situaciones de consistencia parental 
(Benson, Buehler \& Gerard, 2008; Lengua \& Kovacs, 2005; Tildesley \& Andrews, 2008). De todos modos, este importante punto fuerte es, a la vez, su debilidad más saliente: se ha procedido forzando hacia un número de factores determinado teóricamente, $\mathrm{y}$ en aras de aislar soluciones iguales con la misma distribución de reactivos. Sin duda, este estudio preliminar debe ser replicado en otras muestras y confirmado en una cantidad de casos significativamente mayor.

En cuanto a las puntuaciones arrojadas por las subescalas, los reactivos mostraron una adecuada homogeneidad y se observó una buena consistencia interna en la mayoría de las subescalas, en atención al número de elementos que las componen y de la métrica ordinal de las respuestas. El valor aceptable, aunque inferior, en la subescala indiferencia en el Alfa de Cronbach puede deberse a la dificultad para la comprensión de los elementos debido a su formulación negativa; este problema no había surgido en el estudio piloto, por lo que la redacción no fue modificada. Tal dificultad comprensiva también pudo afectar la estabilidad de las puntuaciones; de las correlaciones efectuadas en el test- retest aquella correspondiente a la subescala indiferencia en la versión PADRE no resulta significativa, y en la versión MADRE sí, pero con un valor moderado. La escala Respuesta se ve levemente afectada debido a que su puntuación total incluye la de indiferencia.

En síntesis, los resultados analizados indican que la escala de Estilos Parentales $e$ Inconsistencia Parental Percibida (EPIPP) posee cualidades psicométricas bastante robustas en tanto permite una medición compleja, válida y confiable del constructo estilos parentales percibidos en población de adultos jóvenes. El instrumento deberá ser sometido a estudios que pongan a prueba su invarianza factorial en distintas muestras, así como a análisis de validez convergente y discriminante. Futuros trabajos cumplimentarán esta tarea.

Entre las limitaciones del trabajo también se ubica la muestra utilizada, que no es completamente representativa de toda la población universitaria de la ciudad de Buenos Aires, puesto que el porcentaje de mujeres es mayor al reportado oficialmente (56\%); sin embargo, teniendo en cuenta que en las universidades públicas, y especialmente en la UBA la proporción femenina ronda el $70 \%$, puede pensarse que la muestra analizada no resulta del todo inadecuada (Ministerio de Educación de la Nación, 2009). Otra cuestión a sopesar radica en el hecho de que se hayan incluido pocos estudiantes de instituciones privadas. Los potenciales usuarios del instrumento deberán contemplar este alcance limitado del instrumento, y futuras investigaciones deberán mejorar esta falencia. 
Se espera que la escala aquí presentada sea de utilidad para su uso en los ámbitos de aplicación y de investigación, en el sentido dar respuesta instrumental a un área vacante: la evaluación de estilos parentales percibidos en adultos jóvenes. La indagación sobre los vínculos paterno-filiales vivenciados será evidentemente de mayor interés para el ámbito clínico aplicado, aunque no debe dejar de considerarse la posibilidad de emplear esta herramienta también en tareas de investigación. Si bien en la edad universitaria los estilos de parentalidad vivenciados por los jóvenes no son ya modificables, sus consecuencias a largo plazo merecen ser examinadas, de cara a la implementación de programas educativos para padres de futuras generaciones. La profundización de investigaciones sobre los efectos remotos de cada estilo parental y de las inconsistencias intra e interparentales ayudará a echar luz sobre sus consecuencias reales en la vida de los individuos. Esta escala servirá de herramienta para diseñar estudios retrospectivos en población estudiantil universitaria, evitándose la enorme dificultad de recurrir a costosos seguimientos longitudinales.

\section{Referencias}

Acock, A. C. \& Bengtson, V. L. (1980). Socialization and Attribution Processes: Actual versus Perceived Similarity among Parents and Youth. Journal of Marriage and Family, 42(3), 501515.

Anisman, H., Zaharia, M. D., Meaney, M. J., \& Merali, Z. (1998). Do early-life events permanently alter behavioral and hormonal responses to stressors? International Journal of Developmental Neuroscience 16(3-4), 149-164.

Ausubel, D. P., Balthazar, E. E., Rosenthal, I., Blackman, L. S., Schpoont, S. H., \& Welkowitz, J. (1954). Perceived parent attitudes as determinants of children's ego structure. Child Development, 25(3), 173-183.

Baumrind, D. (1966). Effects of authoritative parental control on child behavior. Child Development, $37,887-907$.

Baumrind, D. (1971). Current patterns of parental authority. Developmental Psychology Monographs, $4(1), 1-103$.

Baumrind, D. (1978). Parental disciplinary patterns and social competence in children. Youth and Society, 9, 239-276.

Baumrind, D. (1980). New directions in socialization research. American Psychologist, 35(7), 639652.

Baumrind, D. (1991a). The influence of parenting style on adolescent competence and substance use. The Journal of Early Adolescence, 11(1), 56-95. 
Baumrind, D. (1991b). Parenting Styles and adolescent development. En J. Brooks-Gunn, R. Lerner \& A. C. Petersen (Eds.), The encyclopedia of adolescence (pp. 746-758). New York: Garland.

Baumrind, D. (1994). The social context of child maltreatment. Family Relations, 43(4), 360-368.

Baumrind, D. (1996a). The discipline controversy revisited. Family Relations: Journal of Applied Family \& Child Studies, 45(4), 405-414.

Baumrind, D. (1996b). A blanket injunction against disciplinary use of spanking is not warranted by the data. Pediatrics, 98(4), 828-831.

Baumrind, D., Larzelere, R. E. \& Cowan, P. A. (2002). Ordinary physical punishment: Is it harmful? Comment on Gershoff. Psychological Bulletin, 128(4), 580-589.

Benson, M. J., Buehler, C. \& Gerard, J. M. (2008). Interparental hostility and early adolescent problem behavior: Spillover via maternal acceptance, harshness, inconsistency, and intrusiveness. The Journal of Early Adolescence, 28(3), 428-454.

Dwairy, M. (2007). Parental inconsistency versus parental authoritarianism: association with symptoms of psychological disorders. Journal of Youth and Adolescence, DOI 10.1007/s10964-007-9169-3.

Dwairy, M. \& Achoui, M. (2006). Introduction to three cross-regional research studies on parenting styles, individuation, and mental health in Arab societies. Journal of Cross-Cultural Psychology, 37(3), 221-229.

Dwairy, M., Achoui, M., Abouserie, R. \& Farah, A. (2006). Parenting styles, individuation, and mental health of Arab adolescents: A third cross-regional research study. Journal of CrossCultural Psychology, 37(3), 262-272.

Dwairy, M. \& Dor, A. (2009). Parenting and psychological adjustment of adolescent immigrants in Israel. Journal of Family Psychology, 23(3), 416-425.

Elosúa, P. \& Zumbo, B. D. (2008). Coeficientes de fiabilidad para escalas de respuesta categórica ordenada. Psicothema, 20(4), 896-901.

Hair, J. F., Anderson, R. E., Tatham, R. L. \& Black, W. C. (1999). Análisis Multivariante. Madrid: Prentice Hall.

Lamm, B. \& Keller, H. (2007). Understanding cultural models of parenting: the role of intracultural variation and response style. Journal of Cross-Cultural Psychology, 38(1), 50-57.

Lee, S. M., Daniels, M. H. \& Kissinger, D. B. (2006). Parental influences on adolescent adjustment: parenting styles versus parenting practices. Family Journal: Counselling and Therapy for Couples and Families., 14(3), 253-259.

Lengua, L. J. (2006). Growth in temperament and parenting as predictors of adjustment during children's transition to adolescence. Developmental Psychology, 42(5), 819-832. 
Lengua, L. J. \& Kovacs, E. A. (2005). Bidirectional associations between temperament and parenting and the prediction of adjustment problems in middle childhood. Journal of Applied Developmental Psychology, 26(1), 21-38.

Lévy Mangin, J. P. \& Varela Mallou, J. (2006). Modelización con Estructuras de Covarianzas en Ciencias Sociales. Coruña: Netbiblo.

Maccoby, E. E. (1994). The role of parents in the socialization of children: An historical overview. En R. D. Parke, P. A. Ornstein, J. J. Rieser \& C. Zahn-Waxler (Eds.), A century of developmental psychology (pp. 589-615). Washington, DC: American Psychological Association.

Maccoby, E. E. \& Martin, J. (1983). Socialization in the context of the family: Parent-child interaction. En E. M. Hetherington \& P. H. Mussen (Eds.), Handbook of child psychology: Vol. 4. Socialization, personality, and social development (pp. 1-101). New York: Wiley.

Martínez Arias, R. (1995). Psicometría: Teoría de los tests psicológicos y educativos. Madrid: Síntesis.

Ministerio de Educación de la Nación (2009). Anuario de Estadísticas Universitarias - Argentina 2009. Buenos Aires: Ministerio de la Nación.

Musitu, G. \& García, F. (2001). ESPA 29. Escala de estilos de socialización parental en la adolescencia. Madrid: TEA.

Richaud de Minzi, M. C. (2002). Inventario acerca de la percepción que tienen los Niños y las Niñas de las Relaciones con sus Padres y Madres. Versión para 4 a 6 años. Revista Interamericana de Psicología, $36(1$ y 2), 149-165.

Richaud de Minzi, M. C. (2005). Versión abreviada del inventario de la percepción de los hijos acerca de las relaciones con sus padres para adolescentes. Psicodiagnosticar, 15, 99-106.

Richaud de Minzi, M. C. (2007). La percepción de estilos de relación con su padre y madre en niños y niñas de 8 a 12 años. Revista Iberoamericana de Evaluación Psicológica, 23(1), 63-81.

Rohner, R. P. (2004). The parental "acceptance-rejection syndrome": Universal correlates of perceived rejection. American Psychologist, 59, 827-840.

Rohner, R. P. (2008) Introduction: Parental acceptance-rejection theory studies of intimate adult relationships. Cross-Cultural Research, 42(1), 5-12.

Rohner, R. P. \& Britner, P. A. (2002). Worldwide mental health correlates of parental acceptancerejection: Review of cross-cultural and intracultural evidence. Cross-Cultural Research, $36(1), 16-47$.

Rohner, R. P., Saavedra, J. \& Granum, E.O. (1978). Development and validation of the parental acceptance rejection questionnaire: test manual. JSAS Catalogue of Selected Documents in Psychology, 8, 7-8.

Rohner, R. P. \& Veneziano, R. A. (2001). The importance of father love: history and contemporary evidence. Review of General Psychology, 5(4), 382-405. 
Rothrauff, T. C., Cooney, T. M. \& An, J. S. (2009). Remembered parenting styles and adjustment in middle and late adulthood. Journal of Gerontology: Social Sciences, 64B(1), 137-146.

Schaefer, E. S. (1965). Children's reports of parental behavior: an inventory. Child Development, 36, 414-424.

Schaefer, E. S. (1997). Integration of configurational and factorial models for family relationships and child behavior. En R. Plutchik \& H. R. Conte (Eds.), Circumplex models of personality and emotions (pp. 133-153). Washington: American Psychological Association.

Serot N. M. \& Teevan R. C. (1961). Perception of the parent-child relationship and its relation to child adjustment. Child Development, 32, 373-378.

Tildesley, E. A. \& Andrews, J. A. (2008). The Development of Children's Intentions to Use Alcohol: Direct and Indirect Effects of Parent Alcohol Use and Parenting Behaviors. Psychology of Addictive Behaviors, 22(3), 326-339.

Varela Mallou, J., Rojas Tejada, A. J. \& Rial Boubeta, A. (2001). Depuración y análisis preliminares de datos en SPSS. Madrid: Ra-Ma. 


\section{ESCALA DE ESTILOS PARENTALES E INCONSISTENCIA PERCIBIDA -EPPIP-}

(de la Iglesia, Ongarato \& Fernández Liporace, 2011)

Te presentamos distintas reacciones que pueden haber tenido tus padres ante distintos comportamientos tuyos en tu adolescencia.

PARTE a) Leé cada posible situación y marcá con qué frecuencia hubiese reaccionado de esa manera tu

PARTE a) PADE y con qué frecuencia hubiese reaccionado de esa manera tu MADRE.

PARTE b) También nos interesa que indiques si las reacciones de tu padre y de tu madre SIEMPRE ERAN LAS MISMAS O CAMBIABAN EN EL TIEMPO.

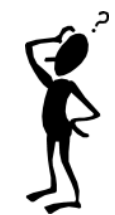

Si alguno de tus padres HA FALLECIDO o NO TENÉS CONTACTO y si vivías con algún adulto que para vos tuvo ese rol en tu vida, CONTESTÁ PENSANDO EN ESA PERSONA.

\begin{tabular}{|c|c|c|c|c|c|c|c|c|}
\hline \multirow{2}{*}{$\begin{array}{l}\text { NO DEJES RESPUESTAS EN BLANCO. } \\
\text { SÉ SINCERO AL CONTESTAR. }\end{array}$} & \multicolumn{4}{|c|}{ MI PADRE } & \multicolumn{4}{|c|}{ MI MADRE } \\
\hline & NUNCA & $\begin{array}{l}\text { ALGUNAS } \\
\text { VECES }\end{array}$ & $\begin{array}{l}\text { MUCHAS } \\
\text { VECES }\end{array}$ & SIEMPRE & NUNCA & $\begin{array}{c}\text { ALGUNAS } \\
\text { VECES }\end{array}$ & $\begin{array}{l}\text { MUCHAS } \\
\text { VECES }\end{array}$ & SIEMPRE \\
\hline \multicolumn{9}{|l|}{$\begin{array}{l}\text { 1. a) Mi padre/madre se hubiese puesto contento/a si le hubiese ofrecido } \\
\text { ayuda sin que me la pidiera. }\end{array}$} \\
\hline $\begin{array}{l}\text { b) Si hacías esto en varias ocasiones, tu padre/madre ireaccionaba } \\
\text { siempre de esa manera? }\end{array}$ & Si & $\square$ & No & $\square$ & Si & $\square$ & No & $\square$ \\
\hline \multicolumn{9}{|l|}{$\begin{array}{l}\text { 2. a) Mi padre/madre se hubiese sentado a hablar del tema conmigo si no } \\
\text { hubiese estudiado o no hubiese querido hacer la tarea. }\end{array}$} \\
\hline $\begin{array}{l}\text { b) Si hacías esto en varias ocasiones, tu padre/madre ¿reaccionaba } \\
\text { siempre de esa manera? }\end{array}$ & $\mathrm{Si}$ & $\square$ & No & $\square$ & Si & $\square$ & No & $\square$ \\
\hline \multicolumn{9}{|l|}{$\begin{array}{l}\text { 3. a) A mi padre/madre no le hubiese parecido importante si mis amigos o } \\
\text { cualquier persona le hubiesen comentado que era buen compañero/a. }\end{array}$} \\
\hline $\begin{array}{l}\text { b) } \mathrm{Si} \text { hacías esto en varias ocasiones, tu padre/madre ireaccionaba } \\
\text { siempre de esa manera? }\end{array}$ & $\mathrm{Si}$ & $\square$ & No & $\square$ & Si & $\square$ & No & $\square$ \\
\hline \multicolumn{9}{|l|}{$\begin{array}{l}\text { 4. a) Mi padre/madre me hubiese retado si me hubiese quedado levantado/a } \\
\text { hasta muy tarde en un día de semana en época de clases. }\end{array}$} \\
\hline $\begin{array}{l}\text { b) Si hacías esto en varias ocasiones, tu padre/madre ireaccionaba } \\
\text { siempre de esa manera? }\end{array}$ & $\mathrm{Si}$ & $\square$ & No & $\square$ & Si & $\square$ & No & $\square$ \\
\hline \multicolumn{9}{|l|}{ 5. a) Mi padre/madre me hubiese golpeado si lo/a hubiese insultado. } \\
\hline $\begin{array}{l}\text { b) Si hacías esto en varias ocasiones, tu padre/madre ireaccionaba } \\
\text { siempre de esa manera? }\end{array}$ & Si & $\square$ & No & $\square$ & Si & $\square$ & No & $\square$ \\
\hline \multicolumn{9}{|l|}{$\begin{array}{l}\text { 6. a) Mi padre/madre me hubiese prohibido algo si me hubiese quedado a } \\
\text { dormir en otra casa sin avisar. }\end{array}$} \\
\hline $\begin{array}{l}\text { b) Si hacías esto en varias ocasiones, tu padre/madre ireaccionaba } \\
\text { siempre de esa manera? }\end{array}$ & $\mathrm{Si}$ & $\square$ & No & $\square$ & Si & $\square$ & No & $\square$ \\
\hline \multicolumn{9}{|l|}{$\begin{array}{l}\text { 7. a) Mi padre/madre me hubiese felicitado si me hubiese sacado buenas } \\
\text { notas. }\end{array}$} \\
\hline $\begin{array}{l}\text { b) Si hacías esto en varias ocasiones, tu padre/madre ireaccionaba } \\
\text { siempre de esa manera? }\end{array}$ & Si & $\square$ & No & $\square$ & Si & $\square$ & No & $\square$ \\
\hline \multicolumn{9}{|l|}{$\begin{array}{l}\text { 8. a) Mi padre/madre se hubiese sentado a hablar del tema conmigo si } \\
\text { hubiese roto o arruinado algo de otra persona o algo de la calle. }\end{array}$} \\
\hline $\begin{array}{l}\text { b) Si hacías esto en varias ocasiones, tu padre/madre ¿reaccionaba } \\
\text { siempre de esa manera? }\end{array}$ & Si & $\square$ & No & $\square$ & Si & $\square$ & No & $\square$ \\
\hline \multicolumn{9}{|l|}{$\begin{array}{l}\text { 9. a) A mi padre/madre no le hubiese parecido importante si hubiese ido } \\
\text { siempre a clases y llegado puntual. }\end{array}$} \\
\hline $\begin{array}{l}\text { b) Si hacías esto en varias ocasiones, tu padre/madre ireaccionaba } \\
\text { siempre de esa manera? }\end{array}$ & $\mathrm{Si}$ & $\square$ & No & $\square$ & Si & $\square$ & No & $\square$ \\
\hline \multicolumn{9}{|l|}{$\begin{array}{l}\text { 10. a) Mi padre/madre me hubiese retado si no hubiese ordenado mi } \\
\text { habitación. }\end{array}$} \\
\hline $\begin{array}{l}\text { b) Si hacías esto en varias ocasiones, tu padre/madre ireaccionaba } \\
\text { siempre de esa manera? }\end{array}$ & Si & $\square$ & No & $\square$ & Si & $\square$ & No & $\square$ \\
\hline \multicolumn{9}{|l|}{$\begin{array}{l}\text { 11. a) Mi padre/madre me hubiese golpeado si hubiese sido insistente y no } \\
\text { hubiese aceptado un "no" como respuesta. }\end{array}$} \\
\hline $\begin{array}{l}\text { b) Si hacías esto en varias ocasiones, tu padre/madre ireaccionaba } \\
\text { siempre de esa manera? }\end{array}$ & $\mathrm{Si}$ & $\square$ & No & $\square$ & Si & $\square$ & No & $\square$ \\
\hline \multicolumn{9}{|l|}{$\begin{array}{l}\text { 12. a) Mi padre/madre me hubiese prohibido algo si me hubiese juntado con } \\
\text { gente que no le caía bien. }\end{array}$} \\
\hline $\begin{array}{l}\text { b) Si hacías esto en varias ocasiones, tu padre/madre ireaccionaba } \\
\text { siempre de esa manera? }\end{array}$ & $\mathrm{Si}$ & $\square$ & No & $\square$ & Si & $\square$ & No & $\square$ \\
\hline
\end{tabular}




\section{NO DEJES RESPUESTAS EN BLANCO.}

SÉ SINCERO AL CONTESTAR.

13. a) Mi padre/madre me lo hubiese agradecido si me hubiese portado bien en casa y no hubiese molestado.

b) Si hacías esto en varias ocasiones, tu padre/madre ireaccionaba siempre de esa manera?

14. a) Mi padre/madre se hubiese sentado a hablar del tema conmigo si le hubiese faltado el respeto.

b) Si hacías esto en varias ocasiones, tu padre/madre ¿reaccionaba siempre de esa manera?

15. a) A mi padre/madre no le hubiese parecido importante si me hubiese cuidado de no ir por zonas peligrosas de la ciudad.

b) Si hacías esto en varias ocasiones, tu padre/madre ireaccionaba siempre de esa manera?

16. a) Mi padre/madre me hubiese retado si hubiese dejado mis cosas tiradas por la casa.

b) $\mathrm{Si}$ hacías esto en varias ocasiones, tu padre/madre ¿reaccionaba siempre de esa manera?

17. a) Mi padre/madre me hubiese golpeado si no le hubiese contestado y le hubiese sido indiferente cuando me hablaba.

b) Si hacías esto en varias ocasiones, tu padre/madre ireaccionaba siempre de esa manera?

18. a) Mi padre/madre me hubiese prohibido algo si hubiese gastado toda la plata que me daban sin permiso.

b) Si hacías esto en varias ocasiones, tu padre/madre creaccionaba siempre de esa manera?

19. a) Mi padre/madre me lo hubiese agradecido si hubiese ayudado a poner la mesa.

b) Si hacías esto en varias ocasiones, tu padre/madre ireaccionaba siempre de esa manera?

20. a) Mi padre/madre se hubiese sentado a hablar del tema conmigo si le hubiese faltado el respeto a algún profesor.

b) Si hacías esto en varias ocasiones, tu padre/madre ireaccionaba siempre de esa manera?

21. a) Mi padre/madre no le hubiese parecido importante si hubiese podido solucionar problemas por mi cuenta.

b) Si hacías esto en varias ocasiones, tu padre/madre ireaccionaba siempre de esa manera?

22. a) Mi padre/madre me hubiese retado si hubiese roto o arruinado alguna cosa de casa.

b) Si hacías esto en varias ocasiones, tu padre/madre ireaccionaba siempre de esa manera?

23. a) Mi padre/madre me hubiese prohibido algo si hubiese ido a boliches/ bares que no le gustaban.

b) Si hacías esto en varias ocasiones, tu padre/madre creaccionaba siempre de esa manera?

24. a) Mi padre/madre hubiese dicho que estaba orgulloso/a de mí si hubiese cuidado mi salud.

b) Si hacías esto en varias ocasiones, tu padre/madre ¿reaccionaba siempre de esa manera?

\begin{tabular}{|c|c|c|c|c|c|c|c|}
\hline \multicolumn{4}{|c|}{ MI PADRE } & \multicolumn{4}{|c|}{ MI MADRE } \\
\hline NUNCA & \begin{tabular}{|c|} 
ALGUNAS \\
VECES
\end{tabular} & $\begin{array}{l}\text { MUCHAS } \\
\text { VECES }\end{array}$ & SIEMPRE & NUNCA & $\begin{array}{l}\text { ALGUNAS } \\
\text { VECES }\end{array}$ & $\begin{array}{l}\text { MUCHAS } \\
\text { VECES }\end{array}$ & SIEMPRE \\
\hline $\mathrm{Si}$ & $\square$ & No & $\square$ & $\mathrm{Si}$ & $\square$ & No & $\square$ \\
\hline $\mathrm{Si}$ & $\square$ & No & $\square$ & $\mathrm{Si}$ & $\square$ & No & $\square$ \\
\hline $\mathrm{Si}$ & $\square$ & No & $\square$ & $\mathrm{Si}$ & $\square$ & No & $\square$ \\
\hline $\mathrm{Si}$ & $\square$ & No & $\square$ & $\mathrm{Si}$ & $\square$ & No & $\square$ \\
\hline $\mathrm{Si}$ & $\square$ & No & $\square$ & $\mathrm{Si}$ & $\square$ & No & $\square$ \\
\hline $\mathrm{Si}$ & $\square$ & No & $\square$ & $\mathrm{Si}$ & $\square$ & No & $\square$ \\
\hline $\mathrm{Si}$ & $\square$ & No & $\square$ & $\mathrm{Si}$ & $\square$ & No & $\square$ \\
\hline $\mathrm{Si}$ & $\square$ & No & $\square$ & $\mathrm{Si}$ & $\square$ & No & $\square$ \\
\hline $\mathrm{Si}$ & $\square$ & No & $\square$ & $\mathrm{Si}$ & $\square$ & No & $\square$ \\
\hline $\mathrm{Si}$ & $\square$ & No & $\square$ & $\mathrm{Si}$ & $\square$ & No & $\square$ \\
\hline $\mathrm{Si}$ & $\square$ & No & $\square$ & $\mathrm{Si}$ & $\square$ & No & $\square$ \\
\hline $\mathrm{Si}$ & $\square$ & No & $\square$ & $\mathrm{Si}$ & $\square$ & No & $\square$ \\
\hline
\end{tabular}


Nombre y apellido:

Edad:

Perfil: PADRE $\square \quad$ MADRE $\square \quad$ Inconsistencia interparental: SI $\square \quad$ NO $\square$ Observaciones:

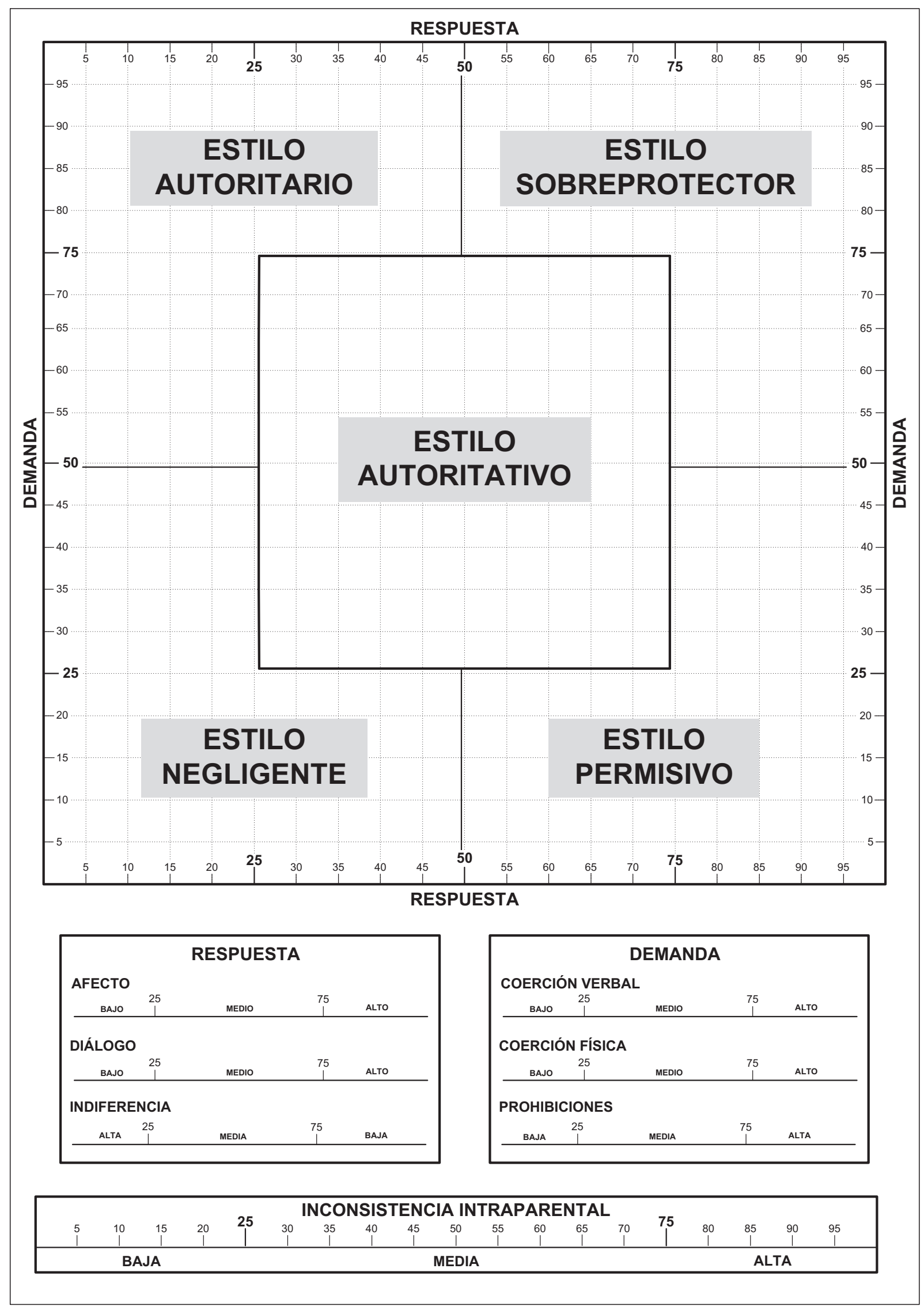

